\section{Food Chemistry}

Vol. 84, Issue 3 , February 2004, Pages 441-446

http://dx.doi.org/10.1016/S0308-8146(03)00266-8

(c) 2003 Elsevier Ltd. All rights reserved
Archimer, archive institutionnelle de l'Ifremer http://www.ifremer.fr/docelec/

\title{
Proteolytic potential in white muscle of sea bass (Dicentrarchus labrax L.) during post mortem storage on ice: time-dependent changes in the activity of the components of the calpain system
}

\author{
Christine Delbarre-Ladrat*, Véronique Verrez-Bagnis, Joëlle Noël and Joël Fleurence
}

IFREMER, DRV-VP-BPQ, BP21105, 44311, Nantes Cedex 3, France

*: Corresponding author : +33-2-40-37-40-00; fax: +33-2-40-37-40-71; cladrat@ifremer.fr

\begin{abstract}
:
The variations in the amounts of milli-calpain and its specific inhibitor in the white muscle of sea bass (Dicentrarchus labrax) during storage at $4{ }^{\circ} \mathrm{C}$ for up to 7 days were determined after separation by hydrophobic chromatography on a Phenyl Sepharose gel. There was a significant decline in postslaughter m-calpain activity with an important inter-individual variability in the rate of decrease of the total activity. In contrast with the calpastatin of mammalian post mortem muscles, calpastatin remained constant within fish muscles after death. The initial levels of protease and inhibitor activities, and their behaviour through post mortem storage, are discussed and implications for the mechanism of tenderisation of fish muscle are suggested.
\end{abstract}

Keywords: Neutral calcium-dependent protease; Calpastatin; Calpain; Fish muscle; Post mortem; Proteolysis 


\section{INTRODUCTION}

The death of an animal initiates major changes in the biochemical features of the muscle tissue leading up to its disintegration. After slaughter, there is a decrease in $\mathrm{pH}$ resulting from an accumulation of lactic acid (Church, 1998; Cottin \& Ducastaing, 1996), a lowering in ATP and a reduction in the integrity of the cell membranes leading to a leakage of free calcium ions in the cytosol (Cottin and Ducastaing, 1996). These changes interact with other biochemical processes occurring after death, especially myofibrillar proteolysis. During the first days of storage in ice, endogenous enzymes are mainly involved in the gradual loss of fish freshness due to a weakening of the myofibrillar structure.

Lysosomal cathepsins, neutral calcium-activated calpains and proteasome are the three proteolytic systems which should bring about the post mortem changes resulting in flesh deterioration even if their roles need further clarification. The study of post mortem proteasome activity of bovine muscle led Lamare et al. (2002) to conclude that proteasome may play a role in meat tenderisation because of its high stability despite the marked decrease in $\mathrm{pH}$ (Lamare, Taylor, Farout, Briand \& Briand, 2002). As for the calpains, a decrease in their activity indicates autolysis and consequently an activation (Saido, Sorimachi \& Suzuki, 1994). They have been suggested to initiate the disintegration of $Z$ line (Astier, Labbe, Roustan \& Benyamin, 1991; Papa, Alvarez, Verrez-Bagnis, Fleurence \& Benyamin, 1996) and further proteolysis may be due to the action of cathepsins and proteasome (Goll, Thompson, Taylor \& Christiansen, 1992; Lamare et al., 2002).

The activity of calpain in post mortem muscles is influenced by several factors including rate of $\mathrm{pH}$ decline, ultimate $\mathrm{pH}$, free calcium ion concentration, compartmentalization within the cell, initial level of its specific endogenous inhibitor (calpastatin) as well as its post mortem decrease and the inactivation of the calpain by autolysis or denaturation. It is likely that the interaction of these factors determines the rate and extent of myofibrillar protein degradation. Calpains have been shown to play an important role in mammals flesh tenderisation (Koohmaraie, 1996; Goll et al., 1998; Ogata, Aranishi, Hara, Osatomi \& Ishihara, 1998) and there is preliminary evidence that the initial post mortem calpain activity and the amount of its specific inhibitor, calpastatin, correlate with the extent of tenderisation in mammalian muscles (Zamora, Debiton, Lepetit, Lebert, Dransfield \& Ouali, 1996). All the studies performed on mammals have demonstrated the same effect of post mortem storage on the activities of the components of the calpain system : gradual loss of $\mu$-calpain and calpastatin and stability or slight loss of m-calpain. The rate of meat tenderisation is related to the enzyme/inhibitor ratio more than to the calpain content. In particular, Thomson et al. (Thomson, Dobbie, Singh \& Speck, 1996) showed that the rapid decline in $\mu$-calpain activity relatively to the calpastatin activity is likely to reduce the degree of tenderisation and ultimate tenderness of bull meat.

Therefore, an enzyme activity may serve as a marker of texture-associated proteolysis. In order to evaluate conservation techniques and to predict early post mortem fish flesh quality, it is important that the material is characterized on its enzymatic activity as it has been studied for mammals (Toldra \& Flores, 2000).

In fish muscle, involvement of calpain activity in post mortem changes remains rather controversial. Our previous studies have been focused on fish calpains in order to understand better the myofibrillar degradation and have shown that in vitro, sea bass m-calpain was able to release myofibril-bound $\alpha$-actinin in soluble fraction (Verrez-Bagnis, Ladrat, Noelle \& Fleurence, 2002). Similarly, Papa et al. (1996) observed a release and a proteolysis of $\alpha$ actinin from the muscle $\mathrm{Z}$ line during refrigerated post mortem storage.

The objective of this study was to characterize initial amounts and time-dependent changes in the activity of the components of the calpain system in post mortem white muscle of sea bass 
(Dicentrarchus labrax). It is composed of three different calpain-like activities depending on the season of slaughter (Ladrat, Chaplet, Verrez-Bagnis, Noël \& Fleurence, 2000) and of calpastatin.

\section{MATERIALS AND METHODS}

Fish and sampling

Five sea bass (Dicentrarchus labrax) were brought alive from a sea farm in Vendée (France) to the laboratory in November and December. Body weights ranged from 180 to $300 \mathrm{~g}$; two of them were females (Table 1). White muscle was excised within 15 min after death by decapitation. Each muscle was stored in whole on ice. Each day up to 6, a $5 \mathrm{~g}$ muscle part was excised, cut into small pieces and used for calpain and calpastatin extraction. The extraction process was performed immediately after sampling for two fish and the three other fish samples were frozen in dry ice and stored at $-80^{\circ} \mathrm{C}$ until the extraction process could be performed (Table 1). Changes of one fish only can be monitored at once by our experimental methods.

Extraction and purification of calpain and calpastatin

Muscle samples (5 g), either frozen or unfrozen, were homogenized in $25 \mathrm{ml}$ of $50 \mathrm{mM}$ Tris $\mathrm{HCl} \mathrm{pH} 7.5$ buffer containing $5 \mathrm{mM}$ beta-mercaptoethanol (ßME) and $5 \mathrm{mM}$ EDTA. After centrifugation, $0.5 \mathrm{M} \mathrm{NaCl}$ was added and the calpains were separated from calpastatin using hydrophobic chromatography by injecting $18 \mathrm{ml}$ on a Phenyl Sepharose CL4B column $(\varnothing 1.6$ $\mathrm{cm}$, L $9 \mathrm{~cm}$, Pharmacia) eluted at $3 \mathrm{ml} / \mathrm{min}$ with $50 \mathrm{mM}$ Tris $\mathrm{HCl} \mathrm{pH} 7$ containing $5 \mathrm{mM}$ BME, $1 \mathrm{mM}$ EDTA and $0.5 \mathrm{M} \mathrm{NaCl}$. Calpastatin was recovered in the nonabsorbed fractions. Calpains were eluted with the same buffer without $\mathrm{NaCl}$ and subsequently dialysed against this elution buffer (noted PHENYL). The eluted calpains were further separated by ion exchange chromatography on a DEAE Sepharose Fast Flow column $(\varnothing 1.6 \mathrm{~cm}, \mathrm{~L} 6 \mathrm{~cm}$, Pharmacia) eluted at $3 \mathrm{ml} / \mathrm{min}$ using a linear gradient of $0-400 \mathrm{mM} \mathrm{NaCl}$. The general procedure has already been described (Ladrat et al., 2000).

Assay of calpain and calpastatin activity

After pooling the active fractions and dialysing to remove salt, m-calpain activity was immediately determined in triplicate as previously described (Ladrat, Verrez-Bagnis, Noel \& Fleurence, 2002) using Suc-Leu-Tyr-AMC as the substrate. One unit of calpain activity was defined as the amount which induces an increase in fluorescence of one unit per min (FSU/min).

Calpastatin activity was measured with a calpain-active sample produced separately from a whole fish white muscle (PHENYL sample) as described above or with a commercially available calpain (SIGMA). Calpastatin extracted from each muscle sample was aliquoted and stored at $4^{\circ} \mathrm{C}$ or $-80^{\circ} \mathrm{C}$ until the end of the post mortem storage. This allowed us to estimate calpastatin inhibitory activity on the very same calpain solution for each sampling since calpain is not fully stable in solution at $4^{\circ} \mathrm{C}$ or in a frozen state. The comparison of the two way of storage of calpastatin extracts may permit the characterization of the effect of freezing on them. One volume of calpastatin sample (or buffer for the control) was mixed with one volume of calpain sample produced in the laboratory and the resulting calpain activity was measured on Suc-Leu-Tyr-AMC substrate as previously described (Ladrat et al., 2002). One unit of calpastatin activity was defined as the amount which inhibited one unit of calpain activity.

Statistical analysis

Experimental values are Means \pm Standard Deviations determined over three replicates. Differences in the mean values from different duration of refrigerated storage of the same fish 
muscle were statistically analysed by the analysis of variance using a $\mathrm{P}$ value of 0.05 . The effect of freezing on calpastatin was evaluated by comparison of the inhibitory activity in extracts (frozen or unfrozen) of the same fish and same post mortem time using paired t-test with a $\mathrm{P}$ value of 0.05 .

\section{RESULTS AND DISCUSSION}

\section{Extraction}

The calpain activity was separated in batch from its inhibitor by hydrophobic chromatography (Phenyl Sepharose). After the subsequent injection of the calpain-active fraction to a DEAE Sepharose Fast Flow column, the elution pattern shows that only one calpain form was recovered (Figure 1). We had previously shown that sea bass white muscle contains three calpain forms differently expressed throughout the year (Ladrat et al., 2000). In winter, one form was completely missing ; it was identified as a low $\mathrm{Ca}^{2+}$-requiring form, $\mu$-calpain. Consequently, the season of fish slaughter for this study as well as the calculated RGS (Table 1) made us expect the absence of this enzymatic form. Nevertheless, the reason why only one m-calpain was recovered is unknown. This is not due to some experimental bias since in the same conditions, the other isoforms have been measured in some other muscles (Ladrat et al., 2000). It is more probably due to individual physiological features of fish. This form has already been fully characterized (Ladrat et al., 2002). This suggest that, in the hypothesis that calpain is responsible for post mortem deterioration of muscle, the forms which are absent in our study have no basic role in this process.

\section{Calpain levels}

Calpain levels were analysed in the PHENYL sample after the first chromatographic column as well as after the DEAE Sepharose Fast Flow chromatography. Initial activity levels are non significantly different between individuals except for fish II. The same evolution patterns were obtained between the two types of preparations (Figure 2). Total calpain activity underwent a progressive and significant decay. After 7 days, residual activity was equal to 0 for one fish muscle (BB) whose calpain content decreased very quickly since no activity was recovered after $96 \mathrm{~h}$ post mortem refrigerated storage. Two fish calpain contents (AA and JJ) showed an intermediate rate of decrease and the two last fish (II and CC) showed only a slight decrease in calpain activity. These results stress the high variability between individual in the rate of decline in activity, the initial level being nearly the same. The decrease in calpain activity could be due to its degradation by other proteases or to its autolytic process occurring when calpain is active (Saido et al., 1994). It would therefore follow that calpain protease is activated during post mortem storage.

Individual differences seem important and may be due to different physiological status. The proteolytic activity has already been shown to vary greatly among species and with the harvesting season, gender maturation, spawning and other variables (Toyohara, Ito, Ando, Kinoshita, Shimizu \& Sakaguchi, 1991). This great variability has also been described in beef (Zamora et al., 1996). The rates of decline of toughness and of $\mu$-calpain and calpastatin activities were significantly different among these animals. These differences are due mainly to metabolic individual characteristics.

Several studies reported a similar decrease in calpain activities. Whereas the activity of mcalpain remained nearly constant or showed a slight decrease, there was a rapid loss of $\mu$ calpain activity during post mortem refrigerated maturation of beef meat (Zamora et al., 1996), rabbit (Vidalenc, Cottin, Merdaci \& Ducastaing, 1983) and bull muscle (Thomson et al., 1996). In ovine muscle, $95 \% \mu$-calpain was lost after $42 \mathrm{~h}$ storage and m-calpain did not undergo autolysis (Veiseth, Shackelford, Wheeler \& Koohmaraie, 2001). The initial levels were also different among the animals (Blanchard \& Mantle, 1996) and in particular, $\mu-$ 
calpain content was higher than m-calpain level in beef muscle (Zamora et al., 1996), but lower in bull (Thomson et al., 1996) and in lamb muscle (Veiseth et al., 2001).

Calpastatin levels

On the contrary, calpastatin levels remain rather constant through post mortem storage (Figure 3). Differences between calpastatin stored at $4^{\circ} \mathrm{C}$ and $-80^{\circ} \mathrm{C}$ are not significant for AA ( $\mathrm{P}=0.783)$, BB $(\mathrm{P}=0.817)$, II $(\mathrm{P}=0.318)$ and $\mathrm{JJ}(\mathrm{P}=0.063)$. Actually, the only noticeable difference is for fish $\mathrm{CC}(\mathrm{P}=0.029)$ for which we can hypothesize an effect of freezing more probably on an unknown and uncontrolled factor able to degrade calpastatin than on calpastatin itself. From this comparison, we can conclude that freezing is a good way of preserving calpastatin activity. Over the five fish tested, the only statistically significant decrease in calpastatin activity as shown in Figure 3 was obtained for fish BB. We can therefore suggest that calpastatin activity remains rather constant in fish muscle over post mortem storage. In mammals, calpastatin activity was shown to be reduced over time storage (Zamora et al., 1996; Thomson et al., 1996). Our results exhibit a different behaviour of fish calpastatin during post mortem storage and suggest a different biochemical processus of tenderisation.

Post mortem transformations involve an increase in the intracellular free calcium ion concentration due to the release from the sarcoplasmic reticulum and mitochondria by increased permeability of the damaged post mortem membranes. The inhibitor serves to protect the enzymes from autolysis in the presence of calcium ions and therefore inhibits its catalytic action. In our study, no calpain activity was detected in the crude extract making the separation on chromatographic column necessary and indicating that calpastatin level is high enough to inhibit all the calpain activity present in the muscle. Unless post mortem muscle contains some factors that enable calpain to be catalytically active in the presence of the calpastatin, it is not clear from these results whether calpain could be responsible for any appreciable post mortem myofibrillar proteolysis. Consequently, it seems likely that activity of the calpain in fish post mortem muscle is modulated by something other than calpastatin or $\mathrm{pH}$ such as localized areas within the cell where the calpains are separated from calpastatin, thereby permitting calpain activation and activity on myofibrillar proteins.

\section{CONCLUSION}

The assay techniques used here measure in vitro the total potential activities of the different components of the calpain system under optimum conditions $\left(\mathrm{pH} 7.5\right.$ and $25^{\circ} \mathrm{C}$ ) with no inhibitors present and in the presence of excess of substrate and free calcium ions. Therefore, they provide an indication of the total potential enzyme activity rather than the actual enzyme activity in the intact muscle sample. Our results indicated that the tenderisation of fish muscle brings some biochemical processes into action which may be different from those in mammalian muscles : absence of the low calcium requiring form rending m-calpain the only neutral calcium-dependent protease potentially active, and stability of post mortem calpastatin activity.

In order to thoroughly identify the protease(s) responsible for post mortem changes, the initial proteolytic potential should be studied in relation to the ultimate tenderness of the muscles ; time-dependent changes in activity should also be studied in relation to the progress of myofibrils degradation or to the progress of tenderisation. Zamora et al. (1996) showed that the richer the muscle was in enzymes, the more tenderised it became. The ultimate tenderness of the muscles was negatively correlated with calpastatin : the richer the muscle was in this inhibitor, the tougher was the meat.

We have previously shown that a sarcoplasmic $16 \mathrm{kDa}$ component was lost during post mortem storage of sea bass muscle in a time-dependent manner. Its disappearance started 
immediately after death and reached a level of $94 \%$ degradation after 96 h (Verrez-Bagnis, Ladrat, Morzel, Noël \& Fleurence, 2001). The release and proteolysis of $\alpha$-actinin in sea bass muscle take place in the early stage of storage i.e. within the first $24 \mathrm{~h}$ (Papa et al., 1996). This indicates that most of post mortem degradations occurred during the first hours of post mortem storage in relation to the maximum of calpain activity as shown in this study. Moreover, $\mathrm{m}$-calpain is able to release and hydrolyse $\alpha$-actinin in vitro (Verrez-Bagnis et al., 2002).

From the calpain system, we found that only m-calpain and calpastatin components are present in these post mortem stored sea bass fillets. To conclude on the role of these components in post mortem proteolysis of myofibrils, proteolytic activity should be assessed on myofibrils. Whether m-calpain and calpastatin come into contact with each other and with myofibrils should also be investigated by performing immunohistology with anti-calpain and anti-calpastatin raised antibodies. 


\section{Reference List}

Astier, C., Labbe, J.-P., Roustan, C., \& Benyamin, Y. (1991). Sarcomeric disorganization in post-mortem fish muscles. Comparative Biochemistry and Physiology, 100B(3), 459465.

Blanchard, P. J., \& Mantle, D. (1996). Comparison of proteolytic enzyme levels in chicken, pig, lamb and rabbit muscle at point of slaughter : role in meat tenderisation post mortem. Journal of Science and Food Agriculture, 71, 83-91.

Church, N. (1998). MAP fish and crustaceans - sensory enhancement. Food Science and Technology Today, 12(2), 73-83.

Cottin, P., \& Ducastaing, A. (1996). Rigor mortis : mécanismes et conséquences. Froid Et Aquaculture, 103-107.

Goll, D. E., Thompson, V. F., Taylor, R. G., \& Christiansen, J. A. (1992). Role of the calpain system in muscle growth. Biochimie, 74, 225-237.

Goll, D. E., Thompson, V. F., Taylor, R. G., \& Ouali, A. (1998). The calpain system and skeletal muscle growth. Canadian Journal of Animal Science, 78(4), 503-512.

Koohmaraie, M. (1996). Biochemical factors regulating the toughening and tenderisation process of meat. Meat Science, 43(S), 193-201.

Ladrat, C., Chaplet, M., Verrez-Bagnis, V., Noël, J., \& Fleurence, J. (2000). Neutral calciumactivated proteases from European sea bass (Dicentrarchus labrax L.) muscle : polymorphism and biochemistry studies. Comparative Biochemistry and Physiology, 125B, 83-95.

Ladrat, C., Verrez-Bagnis, V., Noel, J., \& Fleurence, J. (2002). Milli-calpain from sea bass (Dicentrarchus Labrax) white muscle : purification, characterization of its activity and activation in vitro. Marine Biotechnology, 4(1), 51-62.

Lamare, M., Taylor, R. G., Farout, L., Briand, Y., \& Briand, M. (2002). Changes in proteasome activity during postmortem aging of bovine muscle. Meat Science, 61, 199-204.

Ogata, H., Aranishi, F., Hara, K., Osatomi, K., \& Ishihara, T. (1998). Proteolytic degradation of myofibrillar components by carp cathepsin L. Journal of Science and Food Agriculture, 76, 499-504.

Papa, I., Alvarez, C., Verrez-Bagnis, V., Fleurence, J., \& Benyamin, Y. (1996). Post mortem release of fish white muscle $\alpha$-actinin as a marker of disorganisation. Journal of Science and Food Agriculture, 72(1), 63-70.

Saido, T. C., Sorimachi, H., \& Suzuki, K. (1994). Calpain : new perspectives in molecular diversity and physiological-pathological involvement. Faseb Journal, 8, 814-822.

Thomson, B. C., Dobbie, P. M., Singh, K., \& Speck, P. A. (1996). Post-mortem kinetics of meat tenderness and the components of the calpain system in bull skeletal muscle. Meat Science, 44(3), 151-157. 
Toldra, F., \& Flores, M. (2000). The use of muscle enzymes as predictors of pork meat quality. Food Chemistry, 69(4), 387-395.

Toyohara, H., Ito, K., Ando, M., Kinoshita, M., Shimizu, Y., \& Sakaguchi, M. (1991). Effect of maturation on activities of various proteases and protease inhibitors in the muscle of ayu (Plecoglossus altivelis). Comparative Biochemistry and Physiology, 99B(2), 419-424.

Veiseth, E., Shackelford, S., Wheeler, T., \& Koohmaraie, M. (2001). Effect of postmortem storage on mu-calpain and m-calpain in ovine skeletal muscle. Journal of Animal Science, 79(6), 1502-1508.

Verrez-Bagnis, V., Ladrat, C., Morzel, M., Noël, J., \& Fleurence, J. (2001). Protein changes in postmortem sea bass (Dicentrarchus labrax) muscle monitored by one- and twodimensional gel electrophoresis. Electrophoresis, 22, 1539-1544.

Verrez-Bagnis, V., Ladrat, C., Noelle, J., \& Fleurence, J. (2002). In vitro proteolysis of european sea bass (Dicentrarchus labrax) myofibrillar and sarcoplasmic proteins by an endogenous m-calpain. Journal of the Science and Food Agriculture, 82, 12561262.

Vidalenc, P., Cottin, P., Merdaci, N., \& Ducastaing, A. (1983). Stability of two $\mathrm{Ca}^{2+}$ dependent neutral proteinases and their specific inhibitor during post-mortem storage of rabbit skeletal muscle. Journal of Science and Food Agriculture, 34, 1241-1250.

Zamora, F., Debiton, E., Lepetit, J., Lebert, A., Dransfield, E., \& Ouali, A. (1996). Prediction variability of ageing and toughness in beef $M$. Longissimus lumborum et thoracis. Meat Science, 43(3-4), 321-333. 
Figure 1 : Example of elution of the DEAE Sepharose column. Protein elution was followed by the absorbance at $280 \mathrm{~nm}$. Calpain activity was determined on casein as the substrate for 3 hours as previously described (Ladrat et al., 2000). $\mathrm{NaCl}$ concentration was determined directly in the fractions by refractometry.
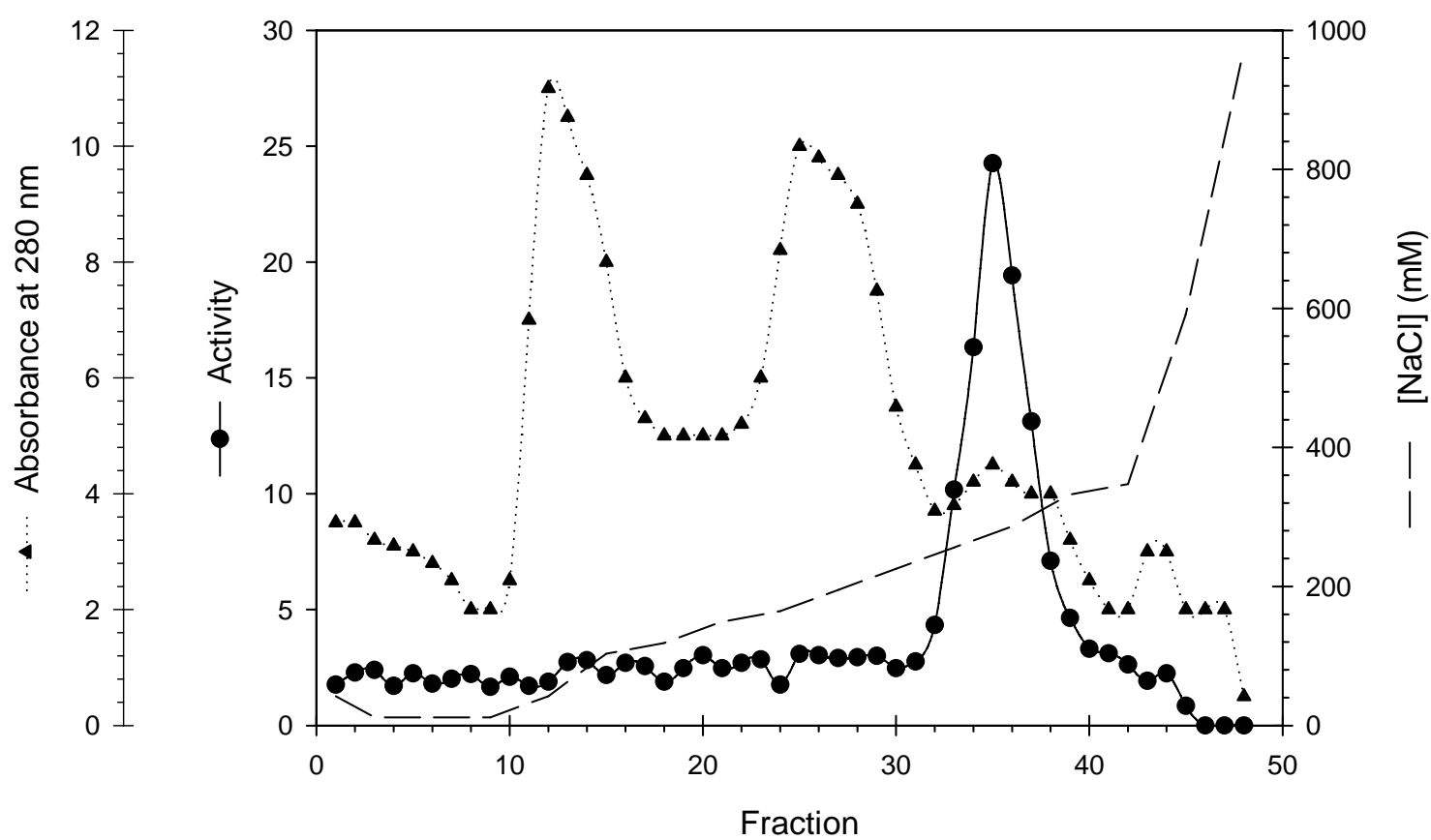

Figure 2 : Calpain activity over post mortem storage of five fish muscles. A : PHENYL sample. B : sample after DEAE chromatography
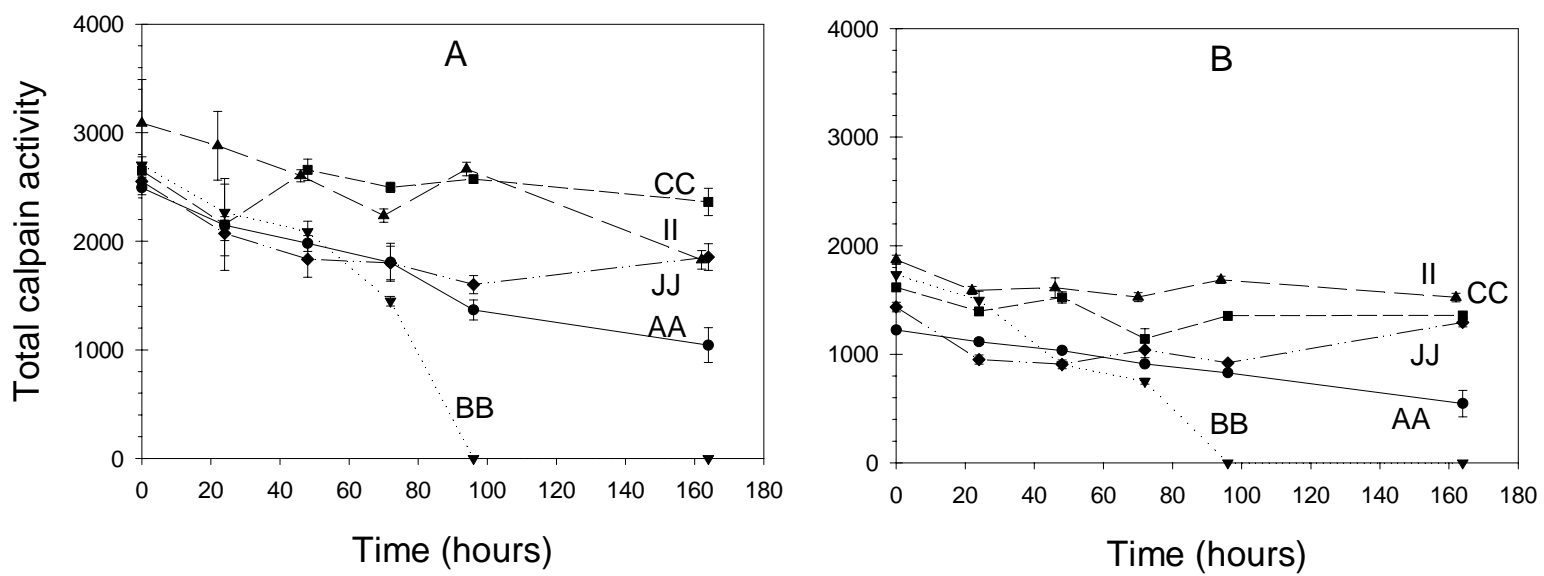
Figure 3: Calpastatin activity over post mortem storage of fish muscle. A : frozen sample. B : samples refrigerated at $4^{\circ} \mathrm{C}$
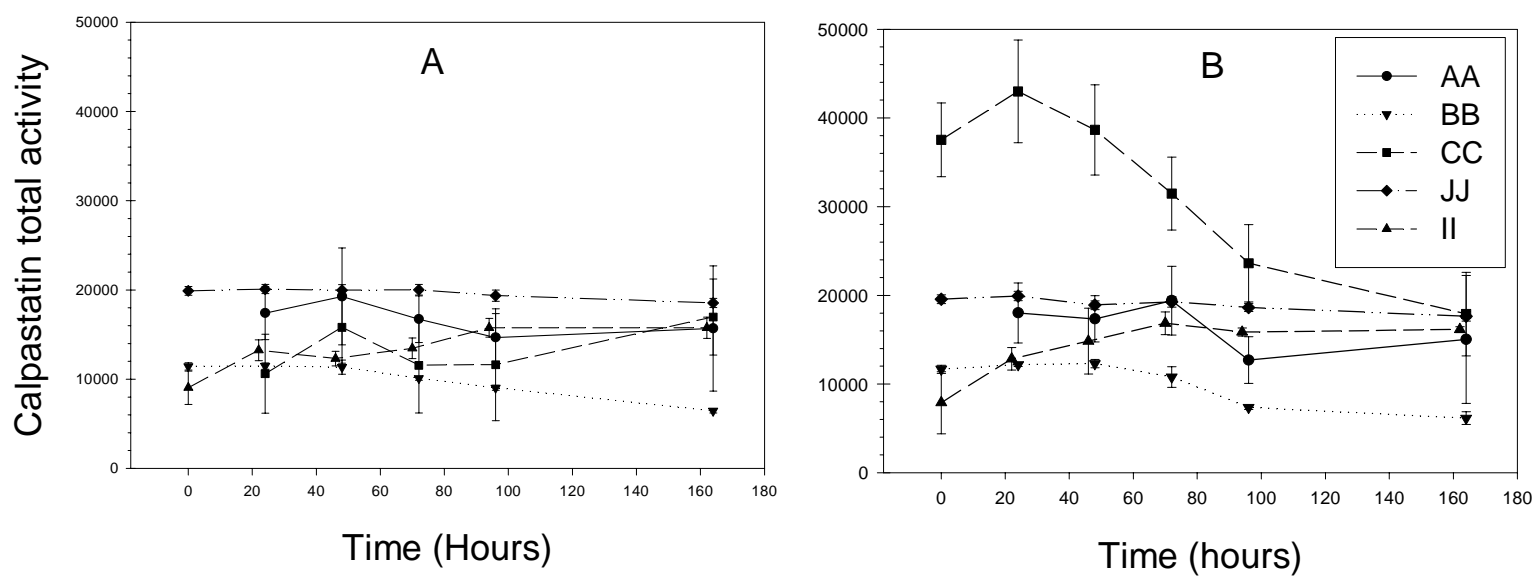

Table 1 : Characteristics of the fish used in this study

\begin{tabular}{cccccc}
\hline Fish & Body weight $(\mathrm{g})$ & Sex & RGS* $^{*}$ & Date & $-80^{\circ} \mathrm{C}$ freezing \\
\hline AA & 180 & M & 0.078 & 6 Nov 2000 & No \\
BB & 290 & M & 0.100 & 6 Nov 2000 & Yes \\
CC & 290 & M & 0.110 & 6 Nov 2000 & Yes \\
II & 300 & F & 1.457 & 4 Dec 2000 & No \\
JJ & 270 & F & 1.041 & 4 Dec 2000 & Yes \\
\hline
\end{tabular}

* : gonado-somatic ratio 